
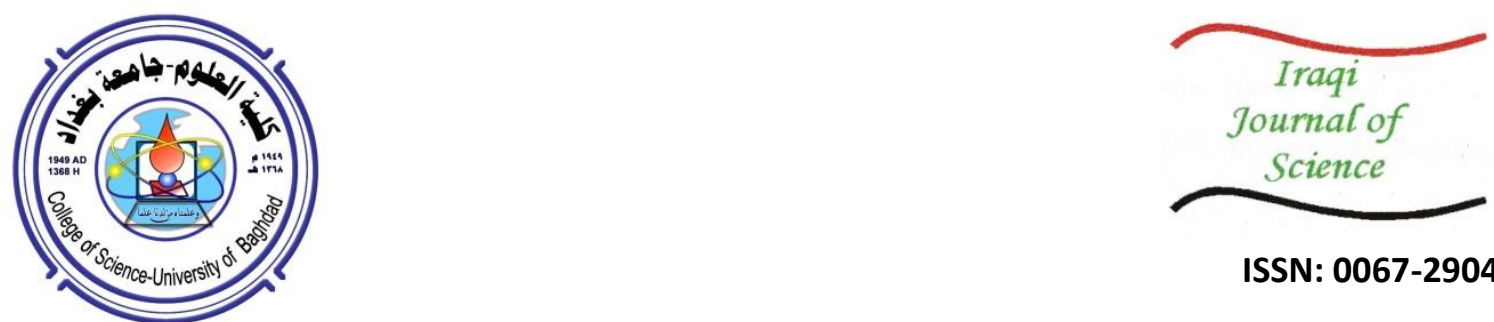

ISSN: 0067-2904

\title{
Molecular detection and identification of Enterococcus faecium isolated from dental root canals
}

\author{
Eman A. Mustafa ${ }^{*}$, Suhad M. Hamdoon, Enas Y. Shehab \\ Department of Dental basic sciences, College of Dentistry, University of Mosul, Mosul, Iraq
}

Received: 5/8/2020

Accepted: 2/11/2020

\begin{abstract}
:
Enterococci are usually encountered and predominate in oral infections, especially those associated with dental root canal infections of necrotic pulp and periodontitis. This study aimed to detect and identify Enterococcus faecium isolated from infected root canals, using polymerase chain reaction ( PCR). Thirty samples were collected from patients with necrotic pulp, infected root canals, and endodontic treatment failure, attending the Conservative Treatment Department, College of Dentistry, Mosul University, Dental Teaching Hospital. The samples were obtained by inserting sterile paper points into the root canals and transferred in brain heart infusion broth vials to be inoculated in a selective M-Enterococcus Agar Base. Twenty five isolates that belong to the genus Enterococcus were recognized by traditional culture methods and biochemical tests. Then, DNA extractions of these isolates were carried out for identification with PCR by the amplification of ddI (D-Ala-D-Ala Ligase) chromosomal genes of Enterococcus faecium. Among the 25 isolates, twenty (80\%) were identified to the level of Enterococcus faecium by traditional culture methods and biochemical tests, in comparison to $17(68 \%)$ identified by molecular identification. The PCR products for the specific primer produced bands on agarose gel at the position of $658 \mathrm{bp}$. The study showed that the use of PCR with primers for the E. faecium ddI gene may be the most accurate method for rapid identification of Enterococci. Molecular

identification of Enterococcus spp. revealed a significant role of E. feacium in root canal infections. Also, the detection of ddI gene using PCR provides a definitive target that could be used for the detection of E. faecium from clinical samples.
\end{abstract}

Key words: Enterococcus faecium, root canal, polymerase chain reaction (PCR)

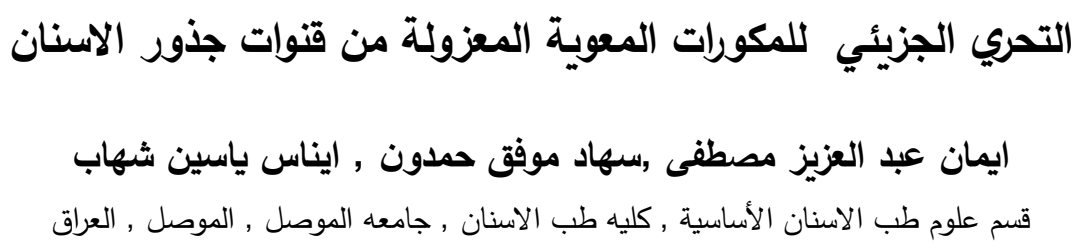

تتواجد المكورات المعوية عاده وتسود في الاصابات الفوية وخاصه تلك المتعلقة بلب السن المتعفن

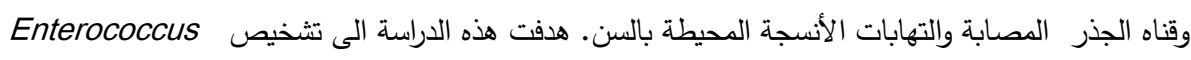

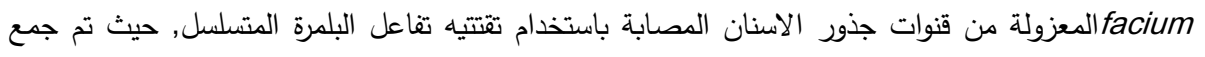

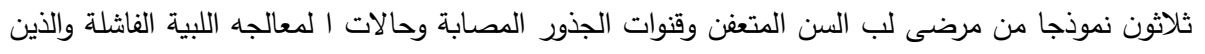

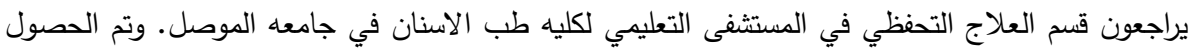

*Email: emanaziz@uomosul.edu.iq 


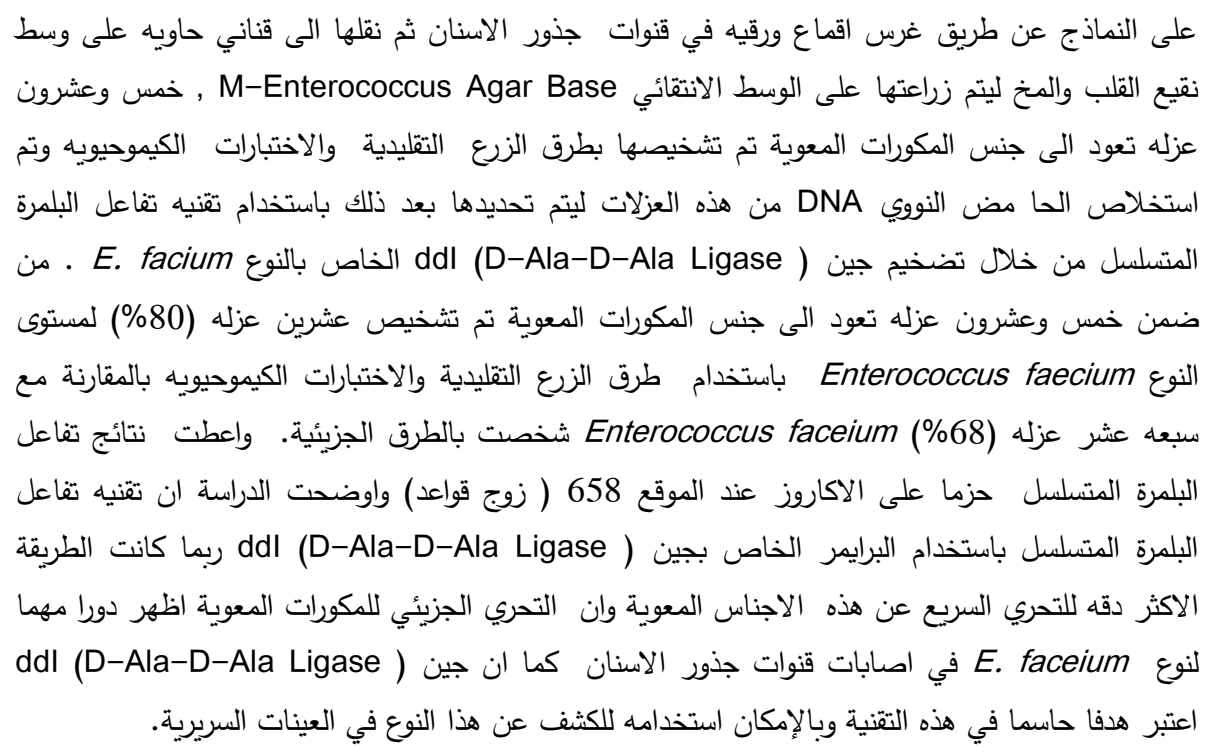

\section{Introduction}

Microorganisms have been presented in all cases associated with endodontic retreatment. Enterococcus spp. was reported to represent the most frequently genus detected in dental root canals [1]. Bacteria could survive in root canals even if good mechanical preparations were performed, causing clinical symptoms such as persistent chronic apical periodontitis [2]. The oral cavity may act as a reservoir for superinfection microorganisms, including E. faecalis, E. faecium and E. coli, as assessed by anti-biotyping studies [3]. Microbial flora that is found in the root canals after endodontic treatment failure is bounded to a small number of commonly gram positive bacterial species, especially Enterococcus spp. [4]. Enterococci are gram positive, facultative anaerobic, organisms that are considered as transitory constituents of the oral microbiome and may cause a diversity of oral and systemic infections [5]. In many studies, E. faecalis and E. faecium have been demonstrated as the most popular species isolated from human oral infections, with corresponding virulence factors such as formation of gelatenase, haemolysis, and biofilm formation. Also these factors were correlated with colonization of the host tissue, competition with other bacteria, alteration of the host defense mechanisms, invasion, and the formation of abscess from toxin or inflammatory processes [6]. Molecular genetic approaches have been used to identify Enterococcus spp. of endodontic infections; the most common molecular methods is the polymerase chain reaction [PCR] that have been widely used to identify bacteria in primary endodontic infections. Since conventional and cultivation identification methods have been proved to have several limitations with respect to microbiological diagnosis, more sensitive techniques may be necessary for accurate characterization of the microbial assembly of root-filled teeth. Species-specific PCR primers such as ddIE. E. faecalis and ddIE. E. faecium were documented as competent for enterococcal species identification by different studies. The use of PCR with these primers may be the simplest molecular approach for highly effective identification of distinct Enterococcus spp., while avoiding the draw backs of commercial kits [7,8].

\section{Materials and methods}

\section{1- Sample collection and bacterial identification}

Thirty dental root canal samples were obtained from patients attending the Dental Teaching Hospital by inserting paper points into the canals, which were then immersed in brain heart infusion broth and cultured on selective M-Enterococcus Agar Base. The Enterococcus isolates were diagnosed to the genus level by using the biochemical tests (Table1) and molecular diagnosis [9].

\section{2- Molecular diagnosis of Enterococcus faecium A- DNA extraction}

DNA extraction of Enterococcus spp. was applied from each sample by picking a single colony with a sterile loop, which was then inoculated into sterile tubes of $5 \mathrm{ml}$ brain heart broth and incubated at $37 \mathrm{C}^{0}$ for $24 \mathrm{hr}$. DNA of the enterococcal isolates was extracted by the use of DNA purification kit, according to the instruction of the manufacture (Jena Bioscience, Germany). 


\section{B- Polymerase chain reaction}

The primers employed for the amplification of ddI (D-Ala-D-Ala Ligase ) chromosomal genes were as follows: $\mathrm{F}$ 5'- TTGAGGCAGACCAGATTGACG $-3^{\prime}$ and R 5'TATGACAGCGACTCCGATTCC-3' [8,10], provided in lyophilized forms (IDT, USA). Working stock was prepared by adding PCR grade water to the required concentration according to the supplier's recommendations. The PCR mixture was performed in $25 \mu 1$ volumes that contained $2 \mu 1$ of template DNA , $2 \mu \mathrm{l}$ of specific primers of E. faecium (ddlE) (R and F), $10 \mu \mathrm{l}$ of $2 \mathrm{x}$ Taq master mix, and $11 \mu 1$ of PCR grade water. PCR was conducted using thermal cycler (Optimus 96G,QLS ,UK) . DNA was amplified by a general PCR technique. An initial denaturation of 5 min at $94^{\circ} \mathrm{C}$ was followed by 35 cycles of denaturation at $94^{\circ} \mathrm{C}$ for $1 \mathrm{~min}$, annealing at $54^{\circ} \mathrm{C}$ for $1 \mathrm{~min}$ and extension at $72^{\circ} \mathrm{C}$ for $1 \mathrm{~min}$, followed by a final extension at $72^{\circ} \mathrm{C}$ for $7 \mathrm{~min}$. DNA samples were observed by using agarose gel electrophoresis ( Jena Bioscience, Germany ) prepared as reported by Mohanty et al. [11], with 1x TBE buffer (Genet Bio, Korea) and 100 bp DNA ladder (Jena Bio- science , Germany ) as a standard molecular weight marker. Electrophoresis was performed using power supply of MP 300V (Major Science, UK), then the agarose gel was placed in a documentation system (Bio Doc Analyze, Germany ) and examined under UV light for documentation and determination of expected bands .

Table 1- The results of the biochemical tests used for the identification of Enterococcus faceium isolated from ....

\begin{tabular}{|c|c|}
\hline Basic Characteristics & Results \\
\hline Growth in Bile esculin medium & Positive (+ve) \\
\hline Catalase & Negative(-ve) \\
\hline Gram staining & Gram positive \\
\hline Growth in 6.5\% NaCl & Positive(+ve) \\
\hline Shape & Cocci \\
\hline Growth at pH 9.6 & Positive (+ve) \\
\hline Fermentation of sugar & $(+\mathrm{ve})$ \\
\hline Lactose & $(+\mathrm{ve})$ \\
\hline Fructose & $(+\mathrm{ve})$ \\
\hline Glucose & $(+\mathrm{ve})$ \\
\hline Lactose & $(+\mathrm{ve})$ \\
\hline Arabinose & \\
\hline
\end{tabular}

Table 2-Numbers of Enterococcus faecium isolated by traditional methods and molecular methods

\begin{tabular}{|c|c|c|}
\hline & No of Enterococcus faecium isolates & Percentage \% \\
\hline Biochemical methods & 20 & $80 \%$ \\
\hline Molecular methods & 17 & $68 \%$ \\
\hline
\end{tabular}

\section{Results and Discussion}

Out of thirty paper point samples obtained from root canals, twenty five isolates of Enterococcus $s p$. were detected according to the conventional methods and biochemical tests. Out of these 25 Enterococcus spp. isolates, twenty (80\%) were identified to the level of Enterococcus faecium by the traditional culture methods and biochemical tests, in comparison to 17 (68\%) isolates identified by molecular identification (Table 2). All the isolates of Enterococcus spp. in the present study were exposed to PCR technique with species-specific primers for E. faecium, based on the detection of specific gene that encodes D-alanine, namely D-alanine Ligase for E. faecium (ddlE). Based on PCR results, seventeen Enterococcus isolates (68\%) were detected as E. faecium. The results confirm the presence of a $658 \mathrm{bpPCR}$ product when compared with the DNA ladder (Figure1). 


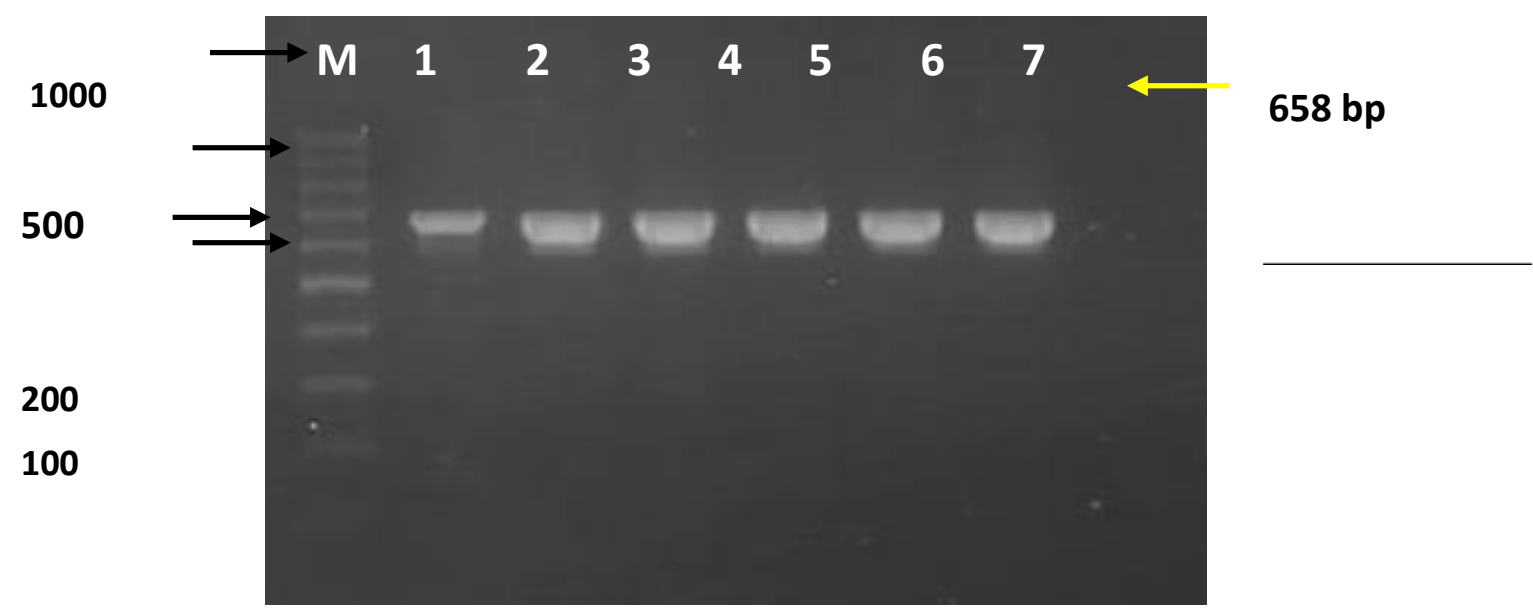

Figure 1-Polymerase chain reaction of Enterococcus faecium. Lane M represents 100 bp DNA marker. Wells 1-6 are positive samples, well 7 is negative control.

The significance of all Enterococcus species in oral infections has not been often contemplated and reported. Even less attention has been given to both phenotypic and genotypic virulent characteristics of these microbes isolated from dental infections [6]. Our study highlights the role of E. feacium in distinction from other Enteroccocuss species, since most previous studies focused mainly on the effects of E. faecalis in the pathogenesis of different oral infections, particularly in root canal infections.

The results of our study showed that E. faecium accounted for $68 \%$ of root canal samples, which agreed with an earlier study that reported that, among Enterococcal species, E. faecalis and $E$ feacium were the most frequently isolated species from the oral cavity, comprising $80 \%$ of clinical samples [5]. Another study demonstrated that E. feacium strains from oral infections had high prevalence of many virulent determinants which play an important role in the pathogenesis of oral infections, including 33/35 (94\%) of esp gene (gene for surface adhesion), 30/35 (86\%) of efaA gene (gene for endocarditis), and 34/35 (97\%) of asal (gene for the aggregation of substances) [6].

The use of PCR and primers that target specific sequences in the ddI genes of the two species $(E$. faecalis and E. faecium) is very important for the identification of the genus and species of Enterococcus. The difficulty in identification of unusual enterococcal strains by phenotypic techniques is not unexpected, especially by using manual commercial kits $[12,13]$. Wrong identification at the genus level and the misidentification of the strains that are repeated in the clinical specimens, such as E. faecalis and E. faecium, are commonly encountered issues. In order to properly detect Enterococcus species, it is essential to perform many introductory tests, including catalase, bile -esculin, PYR, and $6.5 \% \mathrm{NaCl}$ tests. Then, automated device or commercial manual tests must be performed. However, it often appears necessary to conduct further tests, such as pigment production, motility, Dxylose fermentation, Litmus milk reduction, pyruvate utilization, and methyl-a-D-glucopyranoside fermentation. Therefore, molecular approaches could provide a good alternative to these physiological tests [14]. On the other hand, conventional culture-based methods for the identification of Enterococcal spp. require 2-3 days to yield results, while PCR has provided a method for cultureindependent detection of Enterococcal bacteria in a variety of clinical specimens. This assay is capable of yielding accurate results in few hours [15]. Hence, PCR technology provides high specificity and sensitivity and is faster than the conventional methods currently used in hospitals and laboratories $[16,17]$.

\section{Conclusions}

Since traditional phenotypic methods are not highly sufficient, it is recommended to use polymerase chain reaction technique with primers for ddI $E$. facium that provides a rapid, accurate, more sensitive, and less time-consuming detection of these bacteria. 


\section{Acknowledgment}

The authors would like to thank the Department of Basic Science in the College of Dentistry, University of Mosul, for supporting this study .

\section{References}

1. Pereira EB, Ribeiro MB, Soares AJ, Zaia AA, Ferras CC, Marciano MA, Feres M and Gomes BA.2020.Evaluation of the presence of microorganisms from root canal of teeth submitted to retreatment due to prosthetic reasons and without evidence of apical periodontitis . Clinical Oral Investication.24(1).Clinical OralInvestigation.2(4).https $/ /$ doi,org/10.1007/500784-020-030200-z.

2. Rasimick B, Shah R, Musikant B and Deutsch A . 2010.Bacterial colonization of root canaldentine previously treated with endodontic irrigants. AustEndodJ .36(2):7073.DOI: $10.1111 / j .1747-4477.2009 .00193 . x$

3. Gaetti-Jardim E. C, Marqueti A. C , Faverani L P , \& Gaetti-JardimJúnior E. 2010 . Antimicrobial resistance of aerobes and facultative anaerobes isolated from the oral cavity. Journal of Applied Oral Science. 18(6): 551-559 .

4. Niklitschek CR and Oporto GH. 2015.Clinical implications of Enterococcus faecalis microbial contamination in root canals of devitalized teeth: Literature review. Revista OdontologicaMexicana.19(3) :177-182 .DOI: 10.1016/j.rodmex.2016.02.024

5. Komiyama EY, Lepesqueur, LS, Yassuda CG, SamaranayakeLP, Parahitiyawa, NB, Balducci I and Koga-Ito CY.2016 . Enterococcus Species in the Oral Cavity: Prevalence, Virulence Factors and Antimicrobial Susceptibility. Plosone .11(9): e0163001. doi.org/10.1371/journal.pone.0163001

6. Bangalore $\mathrm{H}$, Alkheraif AA, Malash A M ,Hashem MI, Assery MK, Al-asmari M and Durgesh P.2017. Genotypic characterization of enterococcus species isolated from oral cavity and their patterne of antibiotic susceptibility. Asian biomedicine. 10:1(49-53 ): doi org/ 10. 5372 / 19057415.1001 .464 .

7. Kariyama R, Mitsuhata R and Kumon H. . 2000 .Simple and reliable multiplex PCR assay for surveillanceisoletes of VRE. J.Clin. Microb 38: 3092-3095.

8. Kafil HS and Asgharzadeh M. 2014.Vancomycin-Resistant EnteroccusFaecium and Enterococcus Fa-ecalisIsolated from Education Hospital of Iran.Madica Jlini Med.9(4): 323-327.

9. Manro A and Blanch AR . 1999.Identification of Enterococcus spp. with a Biochemical Key. ApplEnviroon. Microbiol.65 (10): 4425-4430

10. Chabuck, Z.A., Al-Charrakh, A.H and Al-Sa'adi,M.K.2012. Identification of Enterococcal Species by Polymerase Chain Reaction Technique, with Study of Some Immunological Features. Med. J. of Babylon.9(4):824-832.

11.MohantyAK,YadavML and ChoudharyS.2017 .Gel electrophoresis of proteins and nucleic acids.In protocols in Semen Biology (Comparing assays). Animal Biology Center, National Dairy Research Institute, India, Springer . 233.DOI 10.1007/978-981-10-5200-2_18.

12.Hamilton-Miller, J. M. T., and S. Shah.1999 . Identification of clinically isolated vancomycinresistant enterococci: comparison of API and BBL .Crystal systems. J. Med. Microbiol. 48:695696.

13. Jensen, T. G., H. B. Konradsen, and B. Bruun.1999 .Evaluation of the rapidID 32 Strep system. Clin. Microbiol. Infect.5:417-423

14. Angeletti S, Lorino G, Gherardi G, Battistoni F, DE-Cesaris M and Diuonzo G. Routine. 2001 Molecular Identification of Enterococci by gene Specific PCR and 16S Ribosomal DNA Sequencing. Journal of clinical Microbiology.39(2):794-797.DOI: 10.1128/JCM.39.2.794797.2001.

15. d'Azevedo, P. A., Santiago, K. A., Furtado, G. H., Pignatari, A. C. C. and Almeida, R. T. 2009.Rapid detection of vancomycin-resistant enterococci (VRE) in rectal samples from Patients admitted to intensive care units. Brazilian J. Infect. Dis. 13(4): 289-293.

16. Al-Temimay IA, Aswad EM.2018.Identification of Cryptococcus neoformans Isolates by PCRITS regions. Iraqi Journal of Science.59 (4A). 1792-1805.

17. Bayram, D.M. and Ali, H.Z. 2017. Molecular Detection of Suspected Leishmania Isolates Using Polymerase Chain Reaction. Iraqi Journal of Science. 58(4B) : 2076-2082. 